\title{
САРКОИДОЗ: ВОЗМОЖНОСТЬ СПОНТАННОЙ РЕМИССИИ
}

\author{
ИРИНА ЮРЬЕВНА ВИЗЕЛЬ, канд. мед. наук, профессор РАЕ, ассистент кафедры фтизиопульмонологии \\ ГБОУ ВПО «Казанский государственный медицинский университет» Минздравсоцразвития РФ, Казань, 420012, \\ ул. Бутлерова, 49, e-mail: tatpulmo@mail.ru
}

\begin{abstract}
Реферат. Представлен обзор исследований и клинических примеров, посвященных возможности спонтанной ремиссии саркоидоза. Обратное развитие саркоидоза чаще происходило в зарубежных клиниках, где исключен контакт больных с туберкулезом и другими инфекционными заболеваниями, которые могут быть триггером гранулематоза. Возможность спонтанной ремиссии не отрицает назначения активной терапии по жизненным показаниям.
\end{abstract}

Ключевые слова: саркоидоз, прогноз, ремиссия, лечение.

\section{SARCOIDOSIS: THE POSSIBILITY OF SPONTANEOUS REMISSION}

IRINA YU. VIZEL, cand. sci. med. phthisiopulmonology chair, Kazan State Medical University, 420012, Kazan, Butlerova str., 49, e-mail: tatpulmo@mail.ru

\begin{abstract}
A review of clinical studies and examples on the possibility of spontaneous remission of sarcoidosis was presented. Regression of sarcoidosis occurred most often in foreign hospitals, where the contact with patients with tuberculosis and other infectious diseases is excluded, which can trigger granulomatosis. The possibility of spontaneous remission does not negate the purpose of active treatment according to vital indications.
\end{abstract}

Key words: sarcoidosis, prognosis, remission, treatment.

C аркоидоз - распространенное заболевание, характеризующееся образованием в различных органах неказеифизирующихся эпителиоидноклеточных гранулем, течение которого широко варьирует. В своем течении саркоидоз может иметь следующие варианты: спонтанная регрессия, регрессия на фоне лечения, стабилизация состояния (спонтанная или после терапии), прогрессирование; волнообразное течение и рецидив. Этиология заболевания неизвестна, что не позволяет пока влиять непосредственно на причину болезни. В ситуации, когда лечение направлено на следствие болезни, применение сильнодействующих средств требует веского обоснования. Большинство контролируемых исследований, направленных на оценку отдаленных результатов стероидной терапии, подвергаются критике по одной или двум позициям: прежде всего, в разработку включались пациенты с двусторонней лимфаденопатей без изменений в легких, для которых типичен хороший прогноз и спонтанные ремиссии, либо стероиды были назначены больным без клинической симптоматики, в отношении которых большинство клиницистов придерживаются правила «жди и наблюдай» (wait and see), прежде чем начать какое-либо лечение (Gibson G.J., 2001).

Под спонтанной инволюцией (ремиссией) следует понимать пусть медленное, но неуклонное обратное развитие патологического процесса, документированное объективными методами исследования и представленное естественному течению без применения терапевтических мер. В ранних сообщениях о лечении саркоидоза один из классиков учения о саркоидозе Льюис Зильцбах (Siltzbach L.E et al., 1974) писал: «Этиология саркоидоза пока ускользает от нас, так же как и точный метод лечения. Трудность состоит отчасти в непредсказуемости спонтанной ремиссии. С этим связаны сообщения об успехе применения солей кальция, золота, мышьяка, йодида калия, хаульмугрового масла, антилепрола и туберкулина».

Отечественные исследования. В одной из лучших отечественных монографий по саркоидозу А.Е.Рабухин и соавт. (Рабухин А.Е., Доброхотова М.Н., Тонитро- ва Н.С., 1975) отмечали, что при саркоидозе І-ІІ стадии всегда есть шанс спонтанной ремиссии. Зарубежные авторы констатировали, что саркоидоз может быть доброкачественным и в $70-80 \%$ случаев сопровождаться спонтанной ремиссией, тогда как число фратальных случаев не превышает 10\% (Fanburg B.L., 1979). А.Г. Хоменко и О. Швайгер рекомендовали наблюдение больных без лечения в течение 2-6 мес (1982). На основании наблюдения за 1520 больными с различными стадиями саркоидоза легких был сделан вывод о стойкости регрессии саркоидоза при спонтанном излечении (Бурова Н.Ю., Туганова В.Е., 1982).

При общем признании возможности спонтанной регрессии процесса частота этого явления существенно различается в отечественных и зарубежных работах. А.Г. Хоменко отмечал $26 \%$ спонтанных ремиссий (Хоменко А.Г., 1983). Профрессор Л.В.Озерова в 1995 г. отмечала $20 \%$ случаев спонтанной регрессии изменений в легких (Озерова Л.В., 1995). При ретроспективном анализе за 25 лет среди 1500 больных саркоидозом в Центральном НИИ туберкулеза РАМН и 20000 амбулаторных больных на 1996 г. спонтанная регрессия имела место у 20,6\%, что позволило рекомендовать не лечить, а наблюдать в течение 1 года больных саркоидозом с впервые выявленными ограниченными изменениями ВГЛУ и легких и нормальной ФВД (Хоменко А.Г., Гедымин Л.Е., Озерова Л.В. и др., 1996). Спустя 3 года в публикации из того же НИИ частота спонтанных ремиссий составляла 8-17\%, а выжидательная тактика в отношении лечения кортикостероидами (в течение 3-6 мес) была рекомендована только для лиц молодого возраста при отсутствии выраженных клинических проявлений заболевания и значительного поражения легочной ткани (Хоменко А.Г., Ерохин В.В., Филиппов В.П. и др., 1999). При обобщении данных больных саркоидозом за период с 1974 по 2001 г. спонтанные ремиссии были в 20\% наблюдений (Озерова Л.В., Романов В.В., Зайцева И.П. и др., 2001). В конце 90-х годов сотрудники другого отечественного научного центра - Московского НИИ фртизиопульмонологии - констатировали спонтанные регрессии в 
52,5\% случаев саркоидоза I стадии, при наступлении полного излечения только в 5\% случаев (Саницкая Л.Н. и др., 1998). Одновременно были опубликованы и менее оптимистичные данные: при саркоидозе внутригрудных лимфатических узлов частота спонтанной регрессии была $12 \%$, при саркоидозе легких 10,7 и 6,9\% при саркоидозе легких и ВГЛУ (Борисов С.Е., Купавцева Е.А., 1998). Тем не менее эти авторы отмечали, что на основании многолетнего наблюдения более чем 5000 больных в течение первых 5 лет с начала заболевания при адекватной терапии стойкая ремиссия саркоидоза достигалась в 90-95\% случаев в зависимости от клинической формы (Борисов С.Е., Купавцева Е.А., Богородская Е.М. и др., 2001).

Сотрудники Московского НПЦ борьбы с туберкулезом, которые проанализировали 1241 случай саркоидоза, считали, что в настоящее время можно говорить не об излечении, а лишь об обеспечении длительной ремиссии этого заболевания (Гармаш Ю.Ю., 2005). В Воронеже обследование и лечение 276 (86,52\%) больных проводилось в стационаре ПТД; 43 (13,48\%) больных - в амбулаторных условиях. Спонтанная регрессия имела место лишь у 15 (4,70\%) больных (Тюхтин Н.С. и др., 2002). На основании наблюдения за 276 больными саркоидозом в условиях противотуберкулезных учреждений было установлено, что спонтанная ремиссия была у $4 \%$ (Шкунов А.Н., 1995).

Более высокая частота спонтанной регрессии и ремиссии встречается при наблюдении больных пульмонологами. Так, по данным Е.И.Шмелева (2004), спонтанная ремиссия была характерна примерно для 2/3 больных. При анализе 150 вновь выявленных больных в Республике Татарстан спонтанная регрессия была установлена в 40\% случаев среди больных І-І стадией саркоидоза (Визель А.А., Насретдинова Г.Р., Исламова Л.В., Визель Е.А., 2006). В течение первого года наблюдения в Республике Татарстан спонтанная ремиссия саркоидоза была отмечена в $34,8 \%$ случаев (Визель И.Ю., Визель А.А., 2010). При наблюдении больных саркоидозом в противотуберкулезных учреждениях частота спонтанных ремиссий невелика и отличается от таковой при наблюдении в пульмонологических и общеклинических учреждениях.

Зарубежные публикации дают более оптимистичные данные. Возможно, это связано с тем, что больных наблюдают в изоляции от туберкулеза и других инфекций, являющихся потенциальными триггерами гранулематозной реакции. В 1982 г. при наблюдении 243 пациентов в течение 10 лет было установлено, что у $87 \%$ больных саркоидозом в течение 2 лет происходило спонтанное уменьшение рентгенологических изменений в легких (Romer F.K., 1982). Американские авторы описали спонтанную ремиссию в $60 \%$ случаев (Baughman R.P., Sharma O.P., Lynch J.P. 3rd., 1998), голландские - в 93,3\% случаев (Drent M., Jacobs J.A., de Vries J. et al., 1999), швейцарские - около $60 \%$ (Schoni M.H., 2000), фрранцузские - 50\% (Londner C. et al., 2011), сербские - 2/3 случаев (Mihailovic-Vucinic V., Jovanovic D., 2008). Есть и менее оптимистичные заключения; так, в ходе исследования, проведенного в Институте легочных заболеваний Черногории, спонтанная ремиссия имела место только в $11 \%$ случаев при I стадии саркоидоза (Pavlovic-Popovic Z., Djuric B., 2002)

В китайской популяции саркоидоз встречается редко, и в большинстве случаев он проявлялся бессимптомной медиастинальной лимфаденопатией (Leung W.K.,
Lei K.I., Yim A. et al., 1998). Изучение прогноза саркоидоза в Японии показало что у 80-90\% больных со стадией I-II происходила спонтанная ремиссия (Sugie T., Hashimoto N., Iwai K., 1994), позднее было показано, что в $76 \%$ случаев изменения (тени) на рентгенограммах органов грудной клетки исчезали в течение 10 лет (Asada K., Chida K., 2002). Сравнительное исследование прогноза течения саркоидоза в Финляндии и Японии свидетельствовало о том, что нормализация рентгенологической картины у японских больных саркоидозом выше, чем у финских - 73\% против 40\% (Pietinalho A., Ohmichi M., Lofroos A.B. et al., 2000).

Случаи спонтанной ремиссии саркоидоза представлены не только в обобщающих аналитических работах, но и в описаниях клинических случаев. В Испании в течение 3 лет наблюдали больную с поражением легких и селезенки и отметили спонтанную ремиссию процесса обеих локализаций. Контроль проводился с помощью РКТ (Arriero J.M. et al., 2000). В другом случае 24-летняя пациентка жаловалась на кашель, одышку и снижение веса в течение 3 мес. На рентгенограмме имелись обширные негомогенные затемнения в обоих легких. Саркоидоз был гистологически подтвержден трансбронхиальной биопсией. После этого больная в течение 6 мес к врачам не обращалась. Когда она обратилась вновь, все симптомы полностью разрешились, на рентгенограмме тени исчезли (McCullough P.C., McCullough A.E., 2002). В Португалии был опубликован случай гистологически подтвержденного саркоидоза у молодой женщины с бессимптомно протекавшей III стадией саркоидоза, спустя год наблюдения наступила спонтанная ремиссия без какого-либо лечения (CemlynJones J. et al., 2009). Японские пульмонологи описали спонтанную регрессию процесса у 46-летней женщины, у которой исчезновение изменений в средостении и легких было доказано посредством ПЭТ и РКТ (Kaneko M. et al., 2008). Даже при саркоидозе ЦНС, который принято считать критическим состоянием с плохим прогнозом, возможно обратное развитие. Японские геронтологи описали 58-летнюю женщину с увеитом и внутригрудной лимфаденопатией, у которой остро развились полидипсия и полиурия, несахарный диабет, а на МРТ было опухание гипофиза и ножки гипофиза. Биопсия поражений кожи подтвердила саркоидоз. Спустя 2 мес все эти изменения прошли спонтанно без применения СКС, что было расценено врачами как атипичное течение саркоидоза ЦНС (Inaba H. et al., 2009). Поражения селезенки и печени, наоборот, относят к частым и бессимптомным проявлениям системного саркоидоза. Французские пульмонологи описали случай саркоидоза этой локализации, выявленный по данным РКТ брюшной полости, который имел спонтанную регрессию (Margery J. et al., 2007).

Значимость ремиссий при назначении терапии. Значимость спонтанной ремиссии, ее высокая частота требуют от врачей очень тщательного отбора пациентов для стартовой стероидной и цитостатической терапии, высокая частота положительного начального клинико-рентгенологического эфффекта, как правило, негативно сказывается на отдаленном прогнозе. Об этом свидетельствовали следующие работы.

У больных саркоидозом хроническая лимфаденопатия средостения или корней легких может присутствовать в течение десятилетий без динамики или при минимальных изменениях. Наблюдение в течение 16 лет позволило авторам сделать заключение о том, 
что параметры активности гранулематозного процесса не отражали длительности и течения саркоидоза, исхода или потребности в лечении (Israel H.L. et al., 1983). По данным сотрудников медицинского колледжа в Вирджинии (Ричмонд, США), бессимптомный саркоидоз часто разрешается спонтанно, и лишь у небольшой части больных развивается хроническое рецидивирующее течение со снижением функции легких, несмотря на применение стероидов (Puryear D.W., Fowler A.A. 3rd, 1996). Сотрудники университета Киото отмечали, что среди нелеченных частота улучшения рентгенологической картины была выше, чем среди леченных. Авторы сделали заключение, что бессимптомно протекающий саркоидоз лечить не следует, а лечение стероидами требуется только для облегчения прогрессирующих симптомов (Nagai S., Izumi Т., 1994). Более высокую частоту последующих рецидивов саркоидоза у пациентов, получавших системные ГКС, чем после спонтанной ремиссии, отмечали и финские клиницисты (Pettersson T., 1998).

Зарубежные авторы рекомендуют изначально наблюдать за пациентами не менее 6 мес (Newman L.S. et al., 1997). Американские пульмонологи из Цинциннати подчеркивают, что не все больные нуждаются в лечении. Как минимум, треть больных вообще не требует лечения. Не ясно, в какой момент следует лечить бессимптомных пациентов, даже если у них имеется распространенный легочный процесс (Baughman R.P., Lynch J.P., 2003). Американский специалист по саркоидозу M.Judson (2000) также отмечал, что поскольку высока вероятность спонтанных ремиссий, а успех начатого лечения часто не влияет на отдаленные результаты, можно рекомендовать не спешить с назначением гормонов и зарезервировать их для больных с тяжелыми или прогрессирующими нарушениями функции легких. Сотрудники Института экологии и генетики микроорганизмов Уральского отделения РАН и Областного клинического диспансера «Фтизиопульмонология» (Пермь) установили, что у всех вновь выявленных пациентов, не получавших ранее гормоны, происходила нормализация состояния иммунной системы, клинически отмечалась ремиссия, а у ранее получавших ГКС стойкой ремиссии достичь не удалось. Ремиссия до 3 лет была констатирована только у больных с впервые выявленным саркоидозом, не получавших ранее глюкокортикостероиды (Кеворков Н.Н. и др., 2002). В Канаде был отмечен случай сочетания саркоидоза легких и позвоночника с бессимптомным течением и спонтанной ремиссией, доказанный биопсией позвонка (Johnson A.K. et al., 2012). В Японии описан случай костного саркоидоза с легочным аспергиллезом, с быстрым разрешением костных проявлений после проведения лечения аспергиллеза интраконазолом (Murakami K. et al., 2011). Не менее экзотически выглядит развитие и спонтанное исчезновение в течение двух лет гистологически доказанного саркоидоза ВГЛУ у 72-летнего мужчины с раком предстательной железы. Показательно, что немецкие врачи не стали лечить саркоидоз, а мониторировали изменения с помощью ПЭТ (Takesh M. et al., 2012).

Собственное наблюдение. 23.11.2001 г., больная М., 1966 года рождения, была направлена к пульмонологу в связи с выявленными при профилактической фрлюорографии двусторонней диссеминации в легких и двусторонней лимфаденопатии. Жалоб она не предъявляла. После флюорографии была дообследована в противотуберкулезном диспансере: подтверждена диссеминация неясного генеза, КУМ (-), реакция Манту с 2 TE - отрицательная, туберкулез был исключен. Больная имела высшее гуманитарное образование, вредных профессий и вредных привычек не имела. В анамнезе был отек Квинке на бета-лактамные антибиотики, весенне-летний поллиноз. При объективном обследовании больная была нормального питания, правильного телосложения. Периферические лимфатические узлы не пальпировались, кожные покровы были чистыми. Тоны сердца были ритмичными, ясными; дыхание - жестким, хрипов не было. АД 115/75, пульс 80. Вентиляционная способность легких была не нарушена. ФЖЕЛ - 115,4\% от должной; ОФВ 1 - 117,5\% от должного; DLCO - 98\% от должной; насыщение крови кислородом - 97\%. В гемограмме: лейкоцитов4,2 Гига/л, СОЭ - 6 мм/час, лимфоцитов в лейкоформуле - 40\%, тромбоцитов - 227 Гига/л. Согласно УЗИ гепато- и спленомегалии не было.

На рис. 1 отражена РКТ больной от 13.12.2001 г. В условиях онкологического диспансера была проведена видеоторакоскопическая биопсия легкого. В ткани

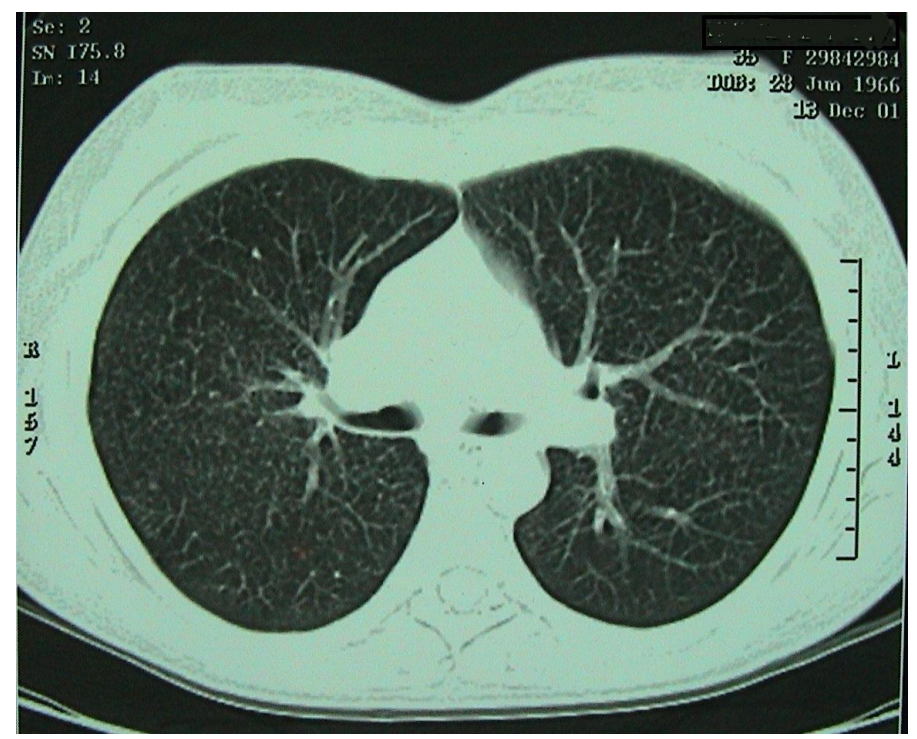

Рис. 1. Рентгеновская компьютерная томограмма (РКТ) больной М. при выявлении саркоидоза: синдром двусторонней диссеминации и умеренная внутригрудная лимфаденопатия 
легкого было описано хроническое гранулематозное воспаление саркоидного типа. Операция прошла без осложнений, пациентка жалоб не предъявляла. Был выставлен клинический диагноз: саркоидоз ВГЛУ и легких, стадия II, гистологически верифицированный, ДН-0. Были назначены пентоксифиллин по 0,2 г 3 раза в день после еды и витамин Е по 200 мг утром и вечером. Однако в течение первой недели лечения развились бессонница, тошнота, преходящая диарея и кожный зуд. Пентоксифиллин был отменен и пациентка получала только витамин Е постоянно. Каждые 3 мес пациентке проводили прямую обзорную рентгенографию, клинический анализ крови, спирографию.
Состояние было удовлетворительным, жалоб не было. 10.07.2002 г. согласно РКТ была выраженная положительная динамика - ВГЛУ сократились в объеме, диссеминация значительно уменьшилась (рис. 2).

ФЖЕЛ - $128 \%$ от должного, ОФВ 1 - $125 \%$, DLCO $108 \%$ от должного, сатурация - 98\%. Больная ежегодно посещала пульмонолога, признаков реактивации не было. 23.04.2004 г. на контрольной РКТ также признаков диссеминации не было (рис. 3). На последней консультации от 21.01.2011 г. была подтверждена полная ремиссия, на прямой (рис. 4) и боковой рентгенограммах лимфаденопатии и диссеминации выявлено не было. Параметры гемограммы и спирограммы

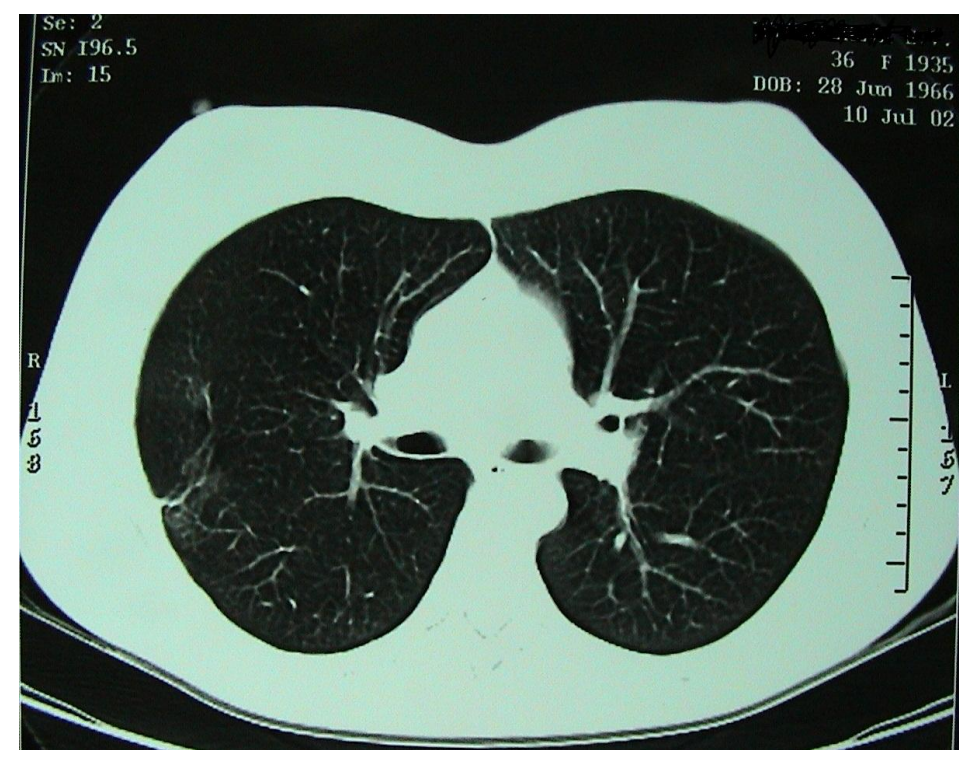

Рис. 2. РКТ легких больной М. спустя 7 мес после выявления. Сохраняются локальные интестициальные изменения в правом легком

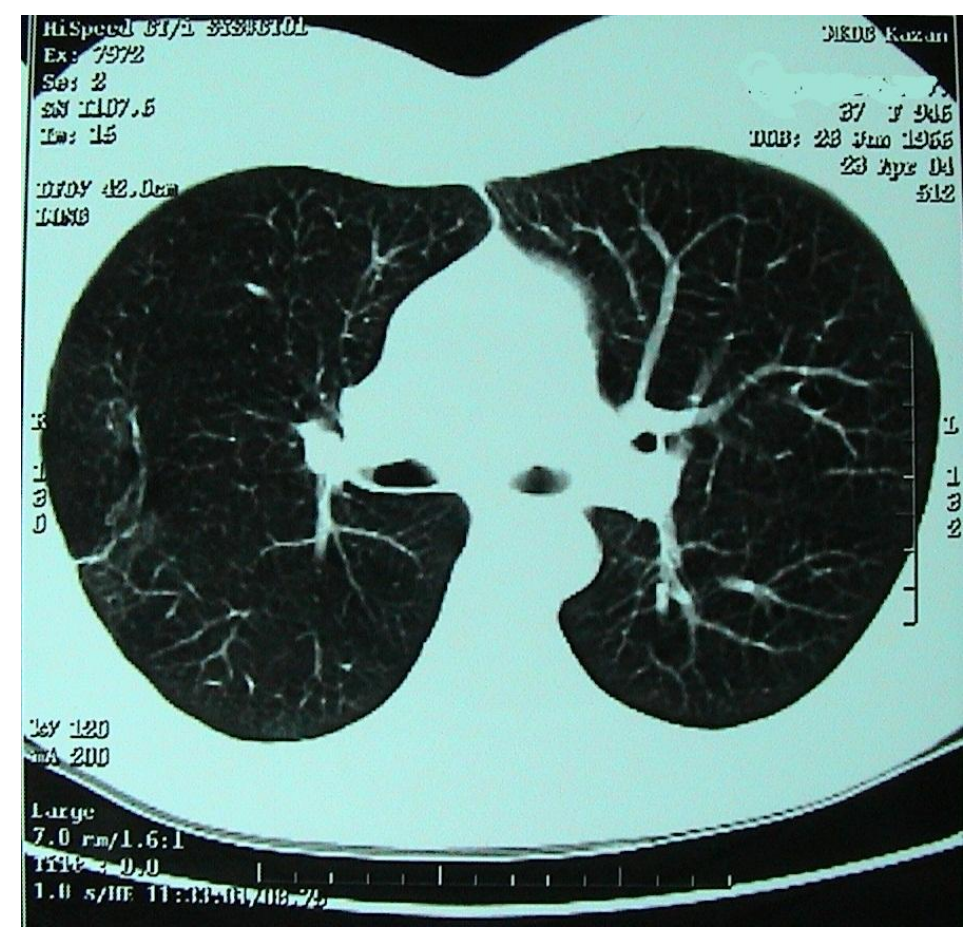

Рис. 3. РКТ легких больной М. спустя 2,5 года после выявления. Ремиссия. Локальные остаточные интерстициальные изменения 


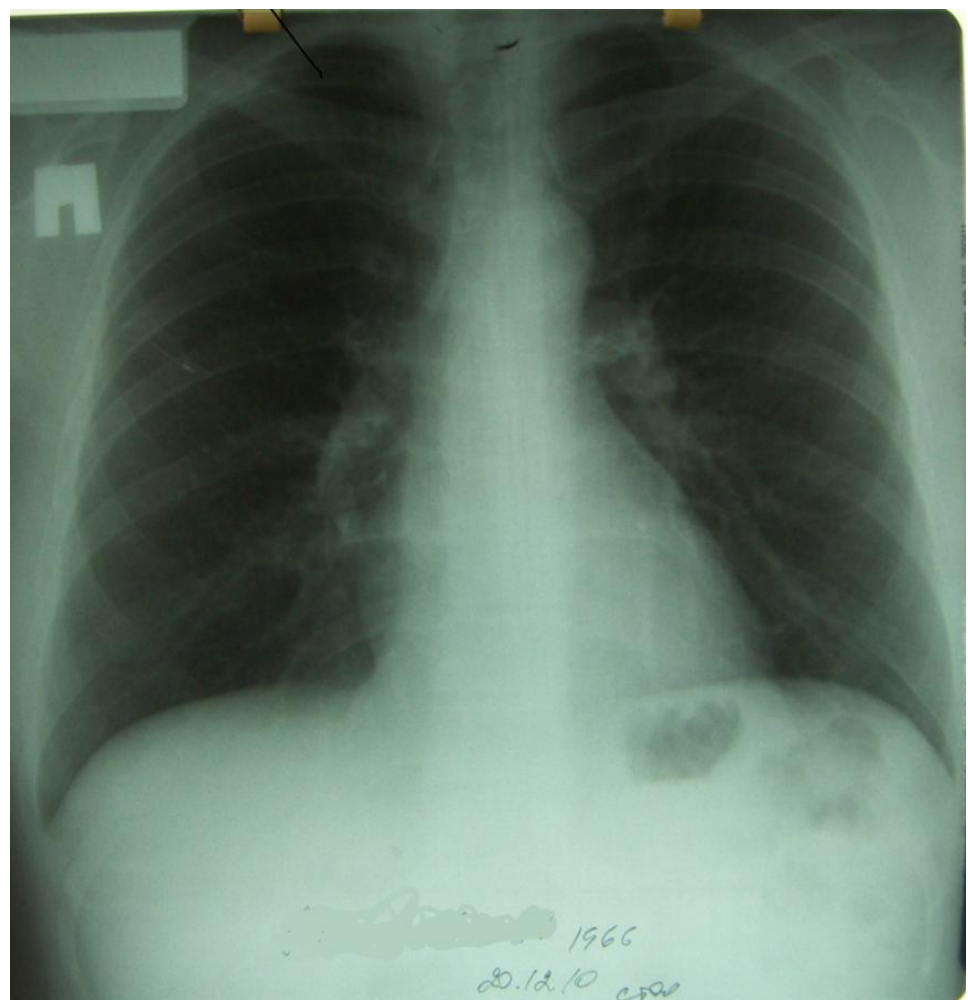

Рис. 4. Прямая обзорная рентгенограмма органов грудной клетки больной М. через 9 лет наблюдения без лечения. Ремиссия

были в пределах нормы. Была констатирована полная ремиссия в течение 8 из 9 лет наблюдения. Данный пример демонстрирует доброкачественное течение саркоидоза у женщины детородного возраста, у которой болезнь протекала бессимптомно с доказанными РКТ диссеминацией и внутригрудной лимфаденопатией, с гистологическим подтверждением диагноза.

Заключение. Анализ исследований и клинических примеров ни в коей мере не отрицает целесообразности применения существующих методов терапии саркоидоза, таких как применение СКС, метотрексата, пентоксифиллина, эфферентных методов терапии и т.д. Однако для начала активной терапии нужны веские причины: диагноз должен быть верифицирован, а врач должен быть уверен в том, что отсутствие лечения будет иметь самые неблагоприятные последствия (остановка сердца, слепота, развитие «сотового легкого» или развитие недостаточности органов или систем).

\section{ЛИТЕРАТУРА}

1. Борисов, С.Е. Лечение саркоидоза / С.Е. Борисов, Е.А. Купавцева // Сборник научных трудов, посвященный 80летию института. - М.: НИИ фттизиопульмонологии ММА им. И.М. Сеченова. - 1998. - С.62-68.

Borisov, S.E. Lechenie sarkoidoza / S.E. Borisov, E.A. Kupavceva // Sbornik nauchnyh trudov, posvjawjonnyj 80-letiju instituta. - M.: NII ftiziopul'monologii MMA im. I.M. Sechenova. - 1998. - S.62-68.

2. Борисов, С.Е. Диагностика и лечение саркоидоза в условиях специализированного центра / С.Е. Борисов, Е.А. Купавцева, Е.М. Богородская [и др.] // Пульмонология. - 2001. - 11-й Национальный конгресс по болезням органов дыхания: сб. резюме. Реф. № XLIII.2. - C.225. Borisov. S.E. Diagnostika i lechenie sarkoidoza v uslovijah specializirovannogo centra / S.E. Borisov, E.A. Kupavceva, E.M. Bogorodskaja [i dr.] // Pul'monologija. — 2001. - 11-j Nacional'nyj kongress po boleznjam organov dyhanija: sb. rezjume. - Ref. № XLIII.2. - S.225.

3. Бурова, Н.Ю. Отдаленные результаты лечения больных саркоидозом органов дыхания / Н.Ю. Бурова, В.Е. Туганова // Проблемы туберкулеза. - 1982. - № 4. - С.46-49. Burova, N.Ju. Otdalennye rezul'taty lechenija bol'nyh sarkoidozom organov dyhanija / N.Ju. Burova, V.E. Tuganova // Problemy tubercul'oza. - 1982. - № 4. - S.46-49.

4. Визель, А.А. Оценка эффективности различных режимов лечения больных вновь выявленным саркоидозом в Республике Татарстан / А.А. Визель, Г.Р. Насретдинова, Л.В. Исламова, Е.А. Визель // Проблемы туберкулеза. 2006. 一№ 4. - C.19-23.

Vizel', A.A. Ocenka jeffektivnosti razlichnyh rezhimov lechenija bol'nyh vnov' vyjavlennym sarkoidozom v Respublike Tatarstan / A.A. Vizel', G.R. Nasretdinova, L.V. Islamova, E.A. Vizel' // Problemy tubercul'oza. - 2006. —№ 4. S.19-23.

5. Визель, И.Ю. Итоги одногодичного наблюдения больных с гистологически верифицированным саркоидозом / И.Ю. Визель, А.А. Визель // Казанский медицинский журнал. - 2010. - Т. XCI (6). - C.724-729.

Vizel', I.Ju. Itogi odnogodichnogo nabljudenija bol'nyh s gistologicheski verificirovannym sarkoidozom / I.Ju. Vizel', A.A. Vizel' // Kazanskij meditsinski zhurnal. — 2010. — T. XCI (6). - S.724-729.

6. Гармаш, Ю.Ю. Роль социально-профессиональных факторов в формировании хронических форм саркоидоза органов дыхания и его рецидивов / Ю.Ю. Гармаш // Проблемы туберкулеза. - 2005. - № 8. - C.54-57.

Garmash, Ju.Ju. Rol' social'no-professional'nyh faktorov v formirovanii hronicheskih form sarkoidoza organov dyhanija i ego recidivov / Ju.Ju. Garmash // Problemy tubercul'oza. 2005. — № 8. - C.54-57.

7. Кеворков, Н.Н. Ликопид в комплексном иммунокорригирующем лечении больных саркоидозом легких и внутригрудных лимфатических узлов / Н.Н. Кеворков, Г.А. Горовиц, С.А. Бахметьев // Терапевт. архив. - 2002. № 3. - C.55-58. 
Kevorkov, N.N. Likopid v kompleksnom immunokorrigirujuwem lechenii bol'nyh sarkoidozom ljogkih i vnutrigrudnyh limfaticheskih uzlov / N.N. Kevorkov, G.A. Gorovic, S.A. Bahmet'ev // Terapevt. arhiv. - 2002 - № 3. S.55-58.

8. Озерова, Л.В. Саркоидоз: диагностика, клиника, течение и лечение / Л.В. Озерова // Проблемы туберкулеза. 1995. — № 4. - C.51-54.

Ozerova, L.V. Sarkoidoz: diagnostika, klinika, techenie i lechenie / L.V. Ozerova // Problemy tubercul'oza. - 1995. № 4 . - S.51-54.

9. Озерова, Л.В. Атипичные и неблагоприятные варианты течения саркоидоза / Л.В. Озерова, В.В. Романов, И.П. Зайцева [и др.] // Проблемы туберкулеза. - 2001. № 7. - C.42-45.

Ozerova, L. V. Atipichnye i neblagoprijatnye varianty techenija sarkoidoza / L.V. Ozerova, V.V. Romanov, I.P. Zajceva [i dr.] // Problemy tubercul'oza. — 2001. —№ 7. - S.42-45.

10. Рабухин, А.Е. Саркоидоз / А.Е. Рабухин, М.Н. Доброхотова, Н.С. Тонитрова. - М.: Медицина, 1975. - 175 с. Rabuhin, A.E. Sarkoidoz / A.E. Rabuhin, M.N. Dobrohotova N.S. Tonitrova. - M.: Medicina, 1975. - $175 \mathrm{~s}$.

11. Саницкая, Л.Н. Особенности клиники и течения саркоидоза I стадии / Л.Н. Саницкая, А.А. Зубков, В.Н. Адамович // Дифференциальная диагностика саркоидоза и туберкулеза легких: сб. / под ред. В.Н. Адамовича. - М., 1998. - C.52-58

Sanickaja, L.N. Osobennosti kliniki i techenija sarkoidoza I stadia / L.N. Sanickaja, A.A. Zubkov, V.N. Adamovich // Differencial'naja diagnostika sarkoidoza i tuberkuleza legkih: sb. / pod red. V.N. Adamovicha. - M., 1998. - S.52-58.

12. Саркоидоз / под ред. А.Г. Хоменко, О. Швайгера (СССРВНР). - М.: Медицина, 1982. — 296 с. Sarkoidoz / pod red. A.G. Homenko, O. Shvajgera (SSSRVNR). - M.:Medicina, 1982. - $296 \mathrm{~s}$.

13. Тюхтин, Н.С. Диспансерное наблюдение больных саркоидозом / Н.С. Тюхтин, М.Ф. Ушакова, Н.А. Стогова, Л.Н. Гришаева // Научно-медицинский вестник Центрального Черноземья. - 2002. - № 10. - С.14-18.

Tjuhtin, N.S. Dispansernoe nabljudenie bol'nyh sarkoidozom / N.S. Tjuhtin, M.F. Ushakova, N.A. Stogova, L.N. Grishaeva // Nauchno-medicinskij vestnik Central'nogo Chernozem'ja. 2002. — № 10. - S.14-18

14. Хоменко, А.Г. Саркоидоз органов дыхания (диагностика и терапия) / А.Г. Хоменко // Клиническая медицина. -1983. — № 12. - С.129-134.

Homenko, A.G. Sarkoidoz organov dyhanija (diagnostika i terapija) / A.G. Homenko // Klinicheskaya meditsina. -1983. - № 12. - S.129-134.

15. Хоменко, А.Г. К этиологии и патогенезу саркоидоза А.Г. Хоменко, Л.Е. Гедымин, Л.В. Озерова [и др.] // Пульмонология. - 1996. - № 6. - С. 154. - Национальный конгресс по болезням органов дыхания. Новосибирск. Pedp. № 0574.

Homenko, A.G. K jetiologii i patogenezu sarkoidoza/ A.G. Homenko, L.E. Gedymin, L.V. Ozerova [i dr.] // Pul'monologija. — 1996. — № 6. - S.154. — Nacional'ny] kongress po boleznjam organov dyhanija. Novosibirs,. Ref. № 0574.

16. Хоменко, А.Г. Саркоидоз как системный гранулематоз / А.Г. Хоменко, В.В. Ерохин, В.П. Филиппов [и др.]. - М.: Медицина, 1999. - 39 с.

Homenko, A.G. Sarkoidoz kak sistemnyj granulematoz I A.G. Homenko, V.V. Erohin, V.P. Filippov [i dr.]. - M.: Medicina, 1999. - $39 \mathrm{~s}$

17. Шкунов, А.Н. Диспансерное наблюдение и эффективность лечения больных саркоидозом / А.Н. Шкунов // Проблемы туберкулеза. - 1995. - № 1. - С.56

Shkunov, A.N. Dispansernoe nabljudenie i jeffektivnost lechenija bol'nyh sarkoidozom / A.N. Shkunov // Problemy tubercul'oza. - 1995. - № 1. - S.56.

18. Шмелев, Е.И. Саркоидоз / Е.И. Шмелев // Атмосфера: Пульмонология и аллергология. - 2004. — № 2 (13). C.3-10.
Shmelev, E.I. Sarkoidoz / E.I. Shmelev // Atmosfera: Pul'monologija i allergologija. — 2004. — № 2 (13). S.3-10.

19. Arriero, J.M. Spontaneous remission of pulmonary and splenic lesions in sarcoidosis / J.M. Arriero, J. Signes-Costa, E. Chiner, J. Marco // Radiography. - 2000. — № 6(4). P.303-306.

20. Asada, K. Prognosis and prognostic factors of sarcoidosis in Japan / K. Asada, K. Chida // Nippon Rinsho. - 2002. Vol. 60(9). - P.1839-1844.

21. Baughman, R.P. Difficult treatment issues in sarcoidosis / R.P. Baughman, J.P. Lynch // J. Intern. Med. - 2003. Vol. 253(1). - P.41-45.

22. Baughman, R.P. Sarcoidosis: is therapy effective? / R.P. Baughman, O.P. Sharma, J.P. Lynch 3rd. // Semin. Respir. Infect. - 1998. - Vol. 13(3). - P.255-273.

23. Cemlyn-Jones, J. Sarcoidosis: a less common presentation / J. Cemlyn-Jones, F. Gamboa, L. Teixeira [et al. // Rev. Port. Pneumol. - 2009. - Vol. 15(3). - P.543-552.

24. Drent, $M$. Does the cellular bronchoalveolar lavage fluid profile reflect the severity of sarcoidosis? / M. Drent, J.A. Jacobs, J. de Vries [et al.] // Eur. Respir. J. — 1999. — Vol. 13(6). P.1338-1344.

25. Fanburg, B.L. Drug therapy reviews: treatment of sarcoidosis / B.L. Fanburg // Am. J. Hosp. Pharm. - 1979. — Vol. 36(3). P.351-354

26. Gibson, G.J. Sarcoidosis: old and new treatments / G.J. Gibson // Thorax. - 2001. - Vol. 56(5). - P.336-339.

27. Inaba, $H$. Spontaneous remission of diabetes insipidus due to CNS sarcoidosis / H. Inaba, S. Suzuki, S. Shigematsu [et al.] // Intern Med. - 2009. — Vol. 48(4). -P.225-229.

28. Israel, H.L. Course of chronic hilar sarcoidosis in relation to markers of granulomatous activity / H.L. Israel, M. Sperber, R.M. Steiner // Invest. Radiol. - 1983. - Vol. 18(1). P.1-5.

29. Johnson, A.K. Spontaneous clinical and radiological resolution of vertebral sarcoidosis: a case report / A.K. Johnson, J.M. Johnson, E. Ames, C. Filippi // Spine (Phila Pa, 1976). 2012. - Vol. 37(6). - P.E414-E416.

30. Judson, M.A. Clinical aspects of pulmonary sarcoidosis / M.A. Judson // J. S. C. Med. Assoc. - 2000. — Vol. 96(1). P.9-17.

31. Kaneko, M. Value of 18F-fluorodeoxyglucose-PET in the diagonosis and monitoring of pulmonary sarcoidosis: a case report / M. Kaneko, H. Tomioka, T. Kaneda [et al.] // Nihon Kokyuki Gakkai Zasshi. - 2008. - Vol. 46(6). P.505-509.

32. Leung, W.K. Sarcoidosis in a Hong Kong Chinese woman W.K. Leung, K.I. Lei, A. Yim [et al.] // Hong Kong Med. J. 1998. - Vol. 4(3). - P.333-336.

33. Londner, C. Treatment of sarcoidosis / C. Londner, I. Zendah, O. Freynet [et al.] // Rev. Med. Interne. - 2011. — Vol. 32(2). P.109-113.

34. Margery, J. Spontaneous regression of hepatic and splenic involvements during sarcoidosis / J. Margery, A. Bonnichon, F. Vaylet [et al.] // Rev. Pneumol. Clin. - 2007. — Vol. 63(2). P.109-110.

35. McCullough, P.C. Nodular sarcoidosis / P.C. McCullough, A.E. McCullough // N. Engl. J. Med. - 2002. — Vol. 346(25). P.1970.

36. Mihailovic-Vucinic, V. Pulmonary sarcoidosis / V. MihailovicVucinic, D. Jovanovic // Clin. Chest Med. - 2008. Vol. 29(3). - P.459-473.

37. Murakami, K. Rapid improvement of osseous sarcoidosis after the treatment of pulmonary aspergillosis by itraconazole / K. Murakami, T. Tamada, K. Abe [et al.] // Sarcoidosis Vasc. Diffuse Lung Dis. - 2011. — Vol. 28(1). - P.75-78.

38. Newman, L.S. Sarcoidosis / L.S. Newman, C.S. Rose, L.A. Maier // N. Engl. J. Med. — 1997. — Vol. 336(17). P.1224-1234.

39. Pavlovic-Popovic, Z. Sarcoidosis: ten year experience / Z. Pavlovic-Popovic, B. Djuric // Abstract book of 7th WASOG Congress in Stockholm, June 16-19. - 2002. - Abstr. № 24 . 
40. Pettersson, T. Rheumatic features of sarcoidosis / T. Pettersson // Curr.Opin.Rheumatol. — 1998. — Vol. 10(1). — P.73-78.

41. Pietinalho, $A$. The prognosis of pulmonary sarcoidosis in Finland and Hokkaido, Japan: A comparative five-year study of biopsy-proven cases / A. Pietinalho, M. Ohmichi, A.B. Lofroos [et al.] // Sarcoidosis Vasc. Diffuse Lung Dis. - 2000. Vol. 17(2). - P.158-166.

42. Romer, F.K. Presentation of sarcoidosis and outcome of pulmonary changes / F.K. Romer // Dan. Med. Bull. — 1982. Vol. 29(1). - P.27-37

43. Schoni, M.H. On the edge of facts and hypotheses / M.H. Schoni // Respiration. - 2000. — Vol. 67(2). — P.135-136.
44. Siltzbach, L.E. Course and prognosis of sarcoidosis around the world / L.E. Siltzbach, D.G. James, E. Neville [et al.] // Am. J. Med. - 1974. - Vol. 57(6). - P.847-852.

45. Sugie, T. Clinical and autopsy studies on prognosis of sarcoidosis / T. Sugie, N. Hashimoto, K. Iwai // Nippon Rinsho. - 1994. - Vol. 52(6). - P.1567-1570.

46. Takesh, M. Incidental detection and monitoring of spontaneous recovery of sarcoidosis via fluorine18-fluoroethyl-choline positron emission tomography/ computed tomography / M. Takesh, U. Haberkorn, L.G. Strauss [et al.] // Hell. J. Nucl. Med. - 2012. Vol. 15(1). - P.63-65.

\title{
СИНДРОМ ОСТРОГО ПОВРЕЖДЕНИЯ ЛЕГКИХ: ОПРЕДЕЛЕНИЕ, ПАТОГЕНЕЗ, ЭКСПЕРИМЕНТАЛЬНЫЕ МОДЕЛИ И РОЛЬ МЕЗЕНХИМАЛЬНЫХ СТВОЛОВЫХ КЛЕТОК ПРИ ЛЕЧЕНИИИ ЖИВОТНЫХ
}

КСЕНИЯ СЕРГЕЕВНА ВОЙТКОВСКАЯ, стУДентка 6-го курса факультета фундаментальной медицины МГУ им. М.В. Ломоносова, Россия, Москва, Ломоносовский пр., 31, корп. 5, e-mail: ksusha-voi@yandex.ru АНДРЕЙ ЛЬВОВИЧ ЧЕРНЯЕВ, Докт. меД. наук, профессор, зав. отделом патологии ФГУ «НИИ пульмонологии» ФМБА России, Москва, ул. 11-я Парковая, 32, e-mail: cheral12@gmail.com

\section{Реферат. Синдром острого повреждения легких (СОПЛ) является клиническим синдромом, имеющим четкие гистологические критерии повреждения структур ткани легкого. СОПЛ имеет широкое распространение в клини- ческой практике и высокую летальность. В статье описаны определение, клиника, этиология, патогенез, экспери- ментальные модели воспроизведения СОПЛ, приведены данные литературы о роли мезенхимальных стволовых клеток (МСК) при лечении СОПЛ у животных, вызванного действием липополисахаридных комплексов. \\ Ключевые слова: синдром острого повреждения легких, эксперимент, липополисахарид, мезенхимальные стволовые клетки. \\ ACUTE LUNG INJURY: THE DEFINITION, PATHOGENESIS, ANIMAL MODELS AND THE ROLE OF MESENCHYMAL STEM CELLS IN EXPERIMENTAL TREATMENT}

KSENIYA S. VOYTKOVSKAYA, student of Faculty of Basic Medicine MSU, Russia, Moscow, Lomonosovskiy prospect, 31, corp. 5, e-mail: ksusha-voi@yandex.ru ANDREY L. CHERNIAEV, MD, professor, head of pathology department FSI "Pulmonary Research Institute" Federal Medical and Biological Agency of Russia, Russia, Moscow, 11th Parkovaya street, 32, e-mail: cheral12@gmail.com

\begin{abstract}
Acute lung injury (ALI) is a clinical syndrome with definite histological criteria of lung structure lesion. ALI is widespread in clinical practice and has a high lethality. In this article we describe the definition, clinics, etiology, pathogenesis, animal models of ALI. In this review we describe a role of mesenchymal stem cells (MSC) in treatment of experimental ALI, induced by lipopolysaccharide.
\end{abstract}

Key words: acute lung injury, experiment, lipopolysaccharide, mesenchymal stem cells.

B первые острый респираторный дистресссиндром (ОРДС) был описан в 1967 г. D.G. Ashbaugh [1]. C тех пор было несколько попыток дать определение ОРДС и СОПЛ [2]. Эти термины можно определить через диагностические критерии, разработанные Американо-европейской согласительной конференцией в 1994 г. [3]: 1) острое начало; 2) дифффузные билатеральные инфильтраты в легком на радиограмме грудной клетке; 3) давление в легочной артерии $\leq 18$ мм рт. ст. или отсутствие клинических признаков гипертензии левого предсердия; 4) при СОПЛ респираторный индекс $\mathrm{PaO}_{2} / \mathrm{FiO}_{2}<300$, при ОРДС $\mathrm{PaO}_{2} / \mathrm{FiO}_{2}<200$. Таким образом, СОПЛ и ОРДС различают по выраженности гипоксемии.
Федерацией анестезиологов и реаниматологов в России принято такое определение: СОПЛ и ОРДС это остро развивающиеся осложнения различных, как правило, тяжелых заболеваний и травм, выражающиеся неспецифическим поражением легких и проявляющиеся клинической картиной быстро нарастающей дыхательной недостаточности, клиниколабораторными признаками прогрессирующего снижения легочного комплайенса, диффузии кислорода через альвеолокапиллярную мембрану, возрастания венозно-артериального шунтирования крови, устранение которых требует применения респираторной поддержки и других методов коррекции кислородтранспортной функции крови [4]. 